\title{
La metrópoli viciosa. Alcohol, crimen y bajos fondos (Ciudad de México, 1929-1946)
}

\author{
Diego Pulido Esteva \\ El Colegio de México, México \\ dpulido@colmex.mx
}

Odette María Rojas Sosa, La metrópoli viciosa. Alcohol, crimen y bajos fondos (Ciudad de México, 1929-1946), México, Universidad Nacional Autónoma de México-Coordinación General de Estudios de Posgrado, 2019.

Este libro se ocupa de las estrategias impulsadas por el régimen posrevolucionario para combatir el consumo excesivo de alcohol en la ciudad de México. Así, es una aportación indiscutible porque explica el peso político y social que adquirió la campaña nacional antialcohólica desde su nacimiento, en 1929, hasta su claudicación tres lustros más tarde, contribuyendo a cubrir un relativo vacío en nuestro conocimiento histórico, como apunta Elisa Speckman en el prólogo.

En otras palabras, Odette Rojas observa los efectos que tuvo la campaña antialcohólica sobre la capital del país, sin perder de vista que durante ese periodo el Estado se abrogó atribuciones morales, sociales y sanitarias para transformar los hábitos libatorios de la población mexicana. Debe decirse que, desde fines del siglo XIX, el gobierno mexicano apostó -salvo en regiones y momentos específicos- por la regulación en lugar de la prohibición del alcohol. En tal sentido, este libro examina un repertorio de medidas de contención, pues las autoridades locales vigilaron, inspeccionarion, impusieron multas, clausuraron o bien concedieron licencias a expendios de bebidas embriagantes, cabarets y salones de baile.

\section{cc) (i) (8)}

4.0 Internacional

Secuencia. Reseñas, 2021

http://secuencia.mora.edu.mx
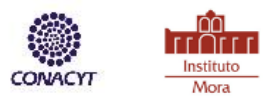
Para analizar dicho proceso, el libro se estructura en seis capítulos. En el primero se presenta un contexto sumamente acabado de la ciudad de México durante el periodo de estudio, precisamente cuando se suprimió el ayuntamiento y se estableció el Departamento Central y luego del Distrito Federal como una medida de centralización administrativa. Pero no solamente se limita a apuntar los cambios en el sistema político, sino que atiende el crecimiento de su traza y su población, así como el surgimiento de nuevas colonias tanto populares como de clases medias. Con ello adquieren mucho mayor sentido los expendios de bebidas embriagantes que se describen en el segundo capítulo: las pulquerías, cervecerías, cantinas y los cabarets aparecen como los principales escenarios que resintieron las medidas restrictivas, aunque no se observa una estricta diferenciación con respecto a periodos anteriores, pues la medida más enérgica fue congelar las licencias.

Ahora bien, cabe precisar que los tívolis no fueron antecedentes del cabaret, pues este espacio tuvo su propia lógica durante el periodo entreguerras y provino, en esencia, de formas de sociabilidad parisinas. Más allá de esta aparente imprecisión, es sumamente sugerente la manera en que se explica la evolución y superposición de otros negocios fagocitados por el cabaret, que experimentó apropiaciones populares en los llamados "rechimales". En números absolutos y relativos descendieron, y probablemente incrementó la clandestinidad. Si bien una gráfica hubiera sido conveniente para el lector, una tabla con cifras detalla el comportamiento de estos establecimientos de 1928 a 1946. Lo cierto es que, además de las tendencias cuantitativas, hubo variantes significativas según el tipo: las cantinas experimentaron una picada de 759 en 1930 a 309 en 1946. Por su parte, las pulquerías experimentaron tendencias estables y promediaron 1 100. En contraste, las cervecerías crecieron y llegaron a ser medio millar. Por último, los cabarets computados por las autoridades pasaron de 36 a 145. Aquí se extraña un análisis más detallado sobre la concurrencia, pues eran espacios de sociabilidad sumamente variados. De la cantina de barrio - que no era sino una tienda con un modesto despacho de bebidas- al salón o cabaret había una distancia casi abismal. Los más 
importantes es que estos últimos tenían un aforo que llegó hasta los siete mil concurrentes semanariamente. ${ }^{1}$

De manera comparable, el libro no resuelve las complicaciones para sostener con base en cifras un supuesto incremento en el consumo, pues el volumen de producción de bebidas embriagantes arroja datos dispares. Pulque y cerveza alcanzaron niveles casi iguales hacia 1942, pero la industria cervecera satisfacía un mercado nacional e incluso de exportacion, mientras que la pulquera experimentó un declive desde la Revolución y su demanda estaba acotada al altiplano central. Es decir, no se señalan consumos diferenciados y no es del todo acertado homologar litro producido con litro ingerido. Sin embargo, esos son límites que alteran poco las tesis esenciales de estudios como el presente. En todo caso, la caracterización de los despachos de bebidas muestra ambientes y sociabilidades con marcadas diferencias de clase, así como políticas discrecionales que favorecieron las cervecerías.

Es absolutamente necesario mostrar el número y distribución por cuartel de los expendios de bebidas, pero una delimitación social más que administrativa queda pendiente para futuras investigaciones. Tal vez el énfasis en las prácticas sociales sea menor con respecto a la atención que se otorga a los discursos e imaginarios. En tal sentido, son de especial interés el tercer y cuarto capítulos, en los que se analizan respectivamente las miradas científicas y "profanas” frente al consumo de alcohol. Si en las primeras figuran médicos y criminólogos, en las segundas difícilmente podríamos convenir que se trata de profanas, pues se analizan exponentes de una prensa confesional: un órgano metodista, como El Evangelista Mexicano, y otro jesuita, como El Mensajero del Sagrado Corazón de Jesús. Estas se complementan con órganos de naturaleza distinta, como revistas de policía, literatura y cine.

Cabe mencionar que los metodistas habían sido los impulsores de sociedades de temperancia desde la segunda mitad del siglo XIX, y no queda clara la fuerza que tenían en la ciudad de México (p. 161). Desde luego suscribían la ley seca vigente hasta 1933 en EU, mientras que al sur del Río Bravo las medidas públicas fueron, acaso, de efectos sumamente ambiguos: se decretó el Día Antialcohólico y se

${ }^{1}$ Ignacio F. Ortiz, "El mundo artificial: un estudio de los cabarets de México, de primera categoría, arroja datos que nunca pasan por la mente del consumidor", Mañana: la revista de México, núm 99, 21 de julio de 1945, pp. 27-31.

E-ISSN 2395-8464 https://doi.org/10.18234/secuencia.v0i0.1961 
celebraban asambleas escolares con la misma consigna. En todo caso, el libro aclara que la agenda educativa y sanitaria de los gobiernos posrevolucionarios incluyó una serie de medidas regulatorias y -pudiera decirse, pedagógicas- como el Congreso contra el Vicio en 1944.

En suma, se siguió una posición moderada y reglamentarista. Salvo experiencias locales o regionales, pero siempre efímeras, el prohibicionismo fue ajeno al contexto mexicano. $\mathrm{Al}$ acoso discursivo correspondían medidas relativamente laxas, como la regulación de licencias y el despliegue de una elocuente pedagogía social, quedando pendiente para investigaciones ulteriores el impulso por medio de las escuelas públicas y el despliegue de cultura física. Como advierte Rojas, el "Estado posrevolucionario pretendió reemplazar a la Iglesia católica en su papel de rectora de conciencias" (p. 191). Los desfiles y otros rituales fueron aparatos de representación para exhibir una ciudadanía ideal, disciplinada y temperante. Lo cierto es que las campañas tuvieron efectos tímidos en la ciudad de México, mientras que instancias como el Comité Nacional de Lucha contra el Alcoholismo, dirigido por el jefe del Departamento de Salubridad y con representantes obreros, campesinos, industriales, así como exponentes de la prensa y secretarías de Estado, fue un órgano sin solidez institucional y con un carácter más bien nominal. Acaso fue prolijo en producir folletos, carteles, conferencias y obras teatrales, pero su poder era difuso. Desaparecería como tal en 1932, creándose la Dirección Antialcohólica de Educación Obrera. Según la autora, la segunda etapa de la campaña se desplegó durante el cardenismo, pero tampoco consolidó instituciones para atender el problema ni queda clara la participación de sujetos fundamentales en la lucha antialcohólica, como las ligas femeninas. Finalmente, la última etapa durante el gobierno de la Unidad Nacional, la ahora denominada Oficina de Educación Antialcohólica mantuvo una apuesta educativa e informativa por medio de cartillas y publicaciones de índole diversa. Así, la gradual pérdida de protagonismo del Estado en el combate contra el alcoholismo "devolvió un mayor peso a la sociedad civil en la causa temperante, como lo demostraría la creación del primer grupo mexicano de Alcohólicos Anónimos (AA) en 1946” (p. 236). Esta tal vez sea una de las conclusiones 
más sugerentes del libro y hubieran sido enriquecedoras evidencias sobre las actividades impulsadas por la sociedad civil durante las campañas.

Uno de los problemas fundamentales para entender históricamente las campañas antialcohólicas es que a veces se confundían con la mera moralización. El capítulo seis se ocupa de reglamentos, infracciones y multas que, a mi modo de ver, poco diferían de las medidas realizadas durante periodos anteriores. De hecho, aparecen como "gran combate" al alcoholismo una serie de trajines en la negociación cotidiana entre el gobierno local y el comercio al menudeo de embriagantes. Por su parte, el séptimo y último capítulo presenta la violencia interpersonal relacionada con la embriaguez sobre una base de 220 expedientes por lesiones en riña.

En resumen, apoyado en una cuidadosa revisión de fuentes administrativas, judiciales y hemerográficas, es un libro a todas luces relevante en el escrutinio histórico de las transgresiones sociales, ocupándose de un conjunto de prácticas en conflicto bajo las coordenadas del binomio ocio y coacción. Por todo lo antes dicho, ayuda a entender el combate contra el alcoholismo emprendido por el Estado posrevolucionario. Posiblemente sea necesario pluralizar y hablar de campañas antialcohólicas para entender las diferentes experiencias locales y los distintos momentos de una "cruzada contra el alcohol". Es sumamente importante contar con investigaciones ulteriores para dar también protagonismo a sujetos sociales en ámbitos escolares y laborales, así como seguir investigando a los pequeños comerciantes y los intereses construidos sobre el consumo de embriagantes. 